\title{
A new approach to resolve problems in the corrosion protection of metals
}

\author{
V. V. Burlov, A. I. Altsybeeva* and T.M. Kuzinova \\ OOO NPO NEPhTEKhIM, ul. Pulkovskaya 10, St. Petersburg, \\ 196158 Russian Federation \\ *E-mail: altsybeeva@yandex.ru
}

\begin{abstract}
It has been shown that corrosion damage of equipment at an oil refinery plant as a common organism is determined by the combined effect of the process media at all stages of operation. Corrosion charts of units have been composed. Methods for the protection of oil refinery plant equipment from local and downtime corrosion, issues of material selection for cladding of surfaces of vessels and pipelines, and an up-to-date scheme of inhibitor protection of oil processing units in operation have been discussed and proposed. A new approach to the choice of starting products and reactions for synthesizing versatile inhibitors of atmospheric corrosion is considered. A new versatile fungicide inhibitor, VNKh-L-408, has been synthesized using this approach.
\end{abstract}

Key words: Oil refinery plants, process media, corrosion charts, local corrosion types, scheme of inhibitor protection for oil refinery plants, versatile corrosion inhibitors.

Received: December 11, 2012.

doi: $\underline{10.17675 / 2305-6894-2013-2-2-092-101}$

The reliability and operating capability of units and various kinds of oil processing equipment depend on strict adherence to the operating regulations and on corrosion factors, on the one hand, and on correct choice of materials during design and on the quality of construction activities, on the other hand.

Currently there are three guiding engineering manuals (GEMs) developed by VNIINeftemash in 1978-84 for selection of construction materials during the design and upgrading of the main units at domestic oil refinery plants. These GEMs are mandatory for design companies and oil refinery plants. Unfortunately, they are obsolete to a considerable degree and nearly no attention is paid therein to the local corrosion of structural metals and alloys. They either lack data on the likelihood of pit and ulcerous corrosion, as well as corrosion cracking, or, conversely, contain overrated data. They also lack data on the composition and corrosivity of deposits and steam treatment condensates that play an important role in the initiation and intensification of both general and local corrosion of metals.

The majority of oil refinery plants in Russian Federation have been put into operation 35-40 years ago. Therefore, the necessity of equipment upgrading and replacement became extremely urgent due to both expiration of the rated equipment life and a considerable 
metal corrosion, especially local corrosion. These circumstances require considerable adjustments in the design standards with consideration for the real corrosion problems found during operation of units.

However, neither the GEMs nor the available international literature treat an oil refinery plant as a common organism with interconnected units that are operated sequentially: "start $\rightarrow$ production mode $\rightarrow$ shutdown (for repair or due to other reasons) $\rightarrow$ steam treatment $\rightarrow$ drying $\rightarrow$ repair $\rightarrow$ start ... etc.", and corrosion damage is determined by the joint effects of the process media at all operation stages.

The main reason of intense corrosion damage of equipment in process units during shutdown and repair periods lies in the presence of deposits in vessels and pipelines. The chemical composition of the deposits and the ratio of various compounds therein are determined by both the type of the process and the quality and composition of the feed stock. The corrosivity of deposits and vapor treatment condensates is comparable to that of feed stocks being processed (Table 1).

For the first time in world practice, we obtained and systematized the full scope of experimental data on all possible types of corrosion damage at domestic crude oil processing units and identified the corrosive agents for various streams and corrosion damage types of vessels during operation in scheduled modes, which allowed us to compose the corrosion charts of units [1]. As an example, Fig. 1 presents the corrosion chart of AT-6 atmospheric column at production enterprise "KINEF".

Industrial tests revealed that pits were formed on all steels. The pit depth is considerable in comparison with the general corrosion rate, particularly on steel $08 \mathrm{Kh} 13$, which is the main cladding material of vessels. This agrees with literature data: the tendency of ferrite steels (08Kh13) to pitting in aqueous solutions is higher than that of austenitic steels.

Operation of vessels under alternating stress is accompanied by a gradual degradation of the metal structure and a decrease in its structural strength. Furthermore, the probability of corrosion cracking grows if pits have appeared and continue growing in the cladding material. Once a pit has formed, its further growth initiates corrosion cracking inevitably. Simple calculations show that, provided that the thickness of the cladding layer from steel $08 \mathrm{Kh} 13$ is $4-6 \mathrm{~mm}$, a deepening pit, even at invariable growth rate, could have degraded cladding completely to the base metal in 25-30 years of column operation and become the main reason of corrosion cracking. It can be considered a well established fact that the main reason of corrosion cracking lies in the high liability of $08 \mathrm{Kh} 13$ steel to pitting corrosion during operation of units under service conditions.

Table 2 provides examples of recorded cases of corrosion cracking at welded joints, weld adjacent zones, and cladding layers of columns in AVT-6 unit at production enterprise "KINEF" where the pit depth on steel $08 \mathrm{Kh} 13$ was considerable. 
Table 1. Mean content of corrosive compounds in the process media at oil refinery plant units (as exemplified by OJSC production enterprise "KINEF")

\begin{tabular}{ccccc}
\hline & & \multicolumn{2}{c}{ Content of corrosive compounds } \\
\cline { 3 - 4 } Medium & pHaq.extract & $\mathbf{C l}^{-}, \mathbf{m g} / \mathbf{d m}^{\mathbf{3}}$ & $\begin{array}{c}\text { Total sulfur, } \\
\text { mass\% }\end{array}$ & H $\mathbf{O}$, vol.\% \\
\hline Crude oil & up to 5.8 & up to 56 & up to 2 & up to 2 \\
Desalted oil & up to 5.6 & up to 6 & up to 2 & up to 0.2 \\
Stripped oil & up to 6.8 & up to 25 & up to 1.4 & none \\
\hline
\end{tabular}

Composition of deposits in oil treatment columns

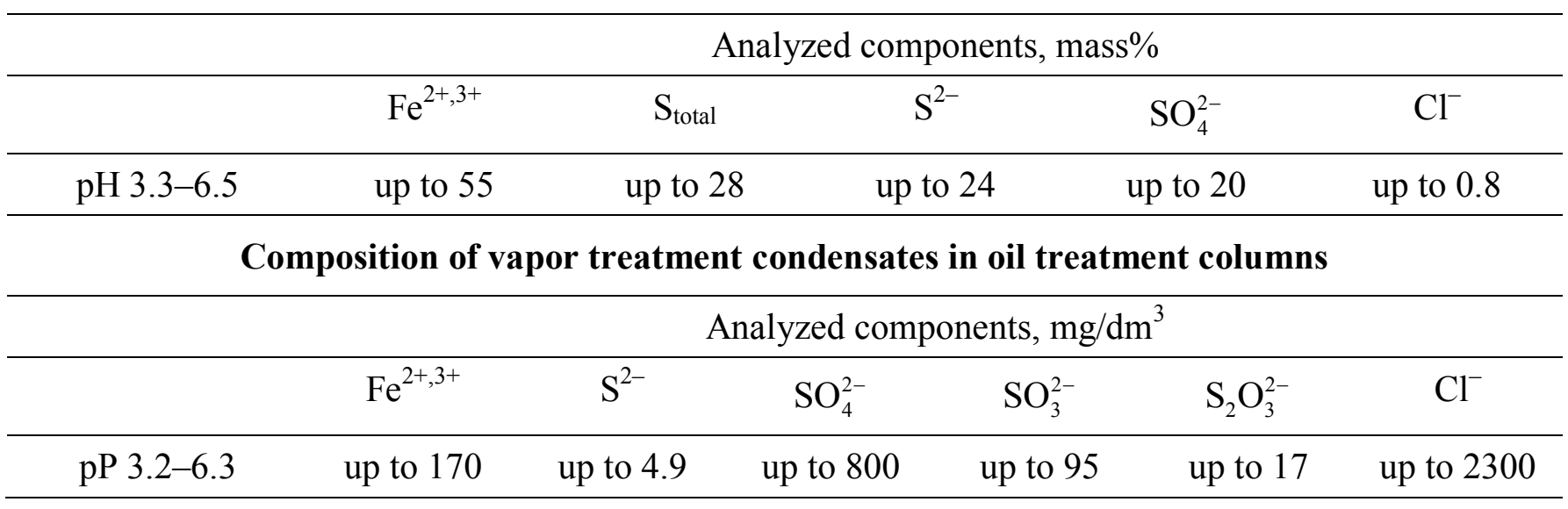

Corrosion cracking problems are usually not observed in one-layer steel columns. However, considerable ulcerous corrosion of lower bottoms was observed therein. Cracks formed due to corrosion cracking in welded joints, weld adjacent zones, and cladding layers in two-layer steels propagated to the main metal, and contact of the environment with carbon steel resulted in enhancement of general corrosion aggravated by a crevice effect in the narrow crack.

On average, four years after identification of the start of corrosion cracking in welded joints and weld adjacent zones, further development of cracks and ulcers in the entire cladding layer was recorded, up to its total delamination from the main metal, total disintegration, or even breakdown of the cladding layer. It is for this reason that scheduled replacement of columns to new ones is currently in progress nearly at all plants.

Similar phenomena are observed in reforming units (Table 3). As an example, Fig. 2 presents photographic images of crevices where one can see that a pit is the start of a crack.

Experience of operation of domestic oil refinery plants and the results of our studies suggest that the existing design standards shall be adjusted considerably: the liability of metals to local corrosion rather than the general corrosion rate should become the determining factor. Poor substantiation and ill choice of steel $08 \mathrm{Kh} 13$ as the cladding material for column equipment of oil processing can be regarded as a well established fact. The search for structural materials with high pitting resistance for replacement of steel 
$08 \mathrm{Kh} 13$ currently used for cladding of columns and other equipment items is a highly important and urgent task.

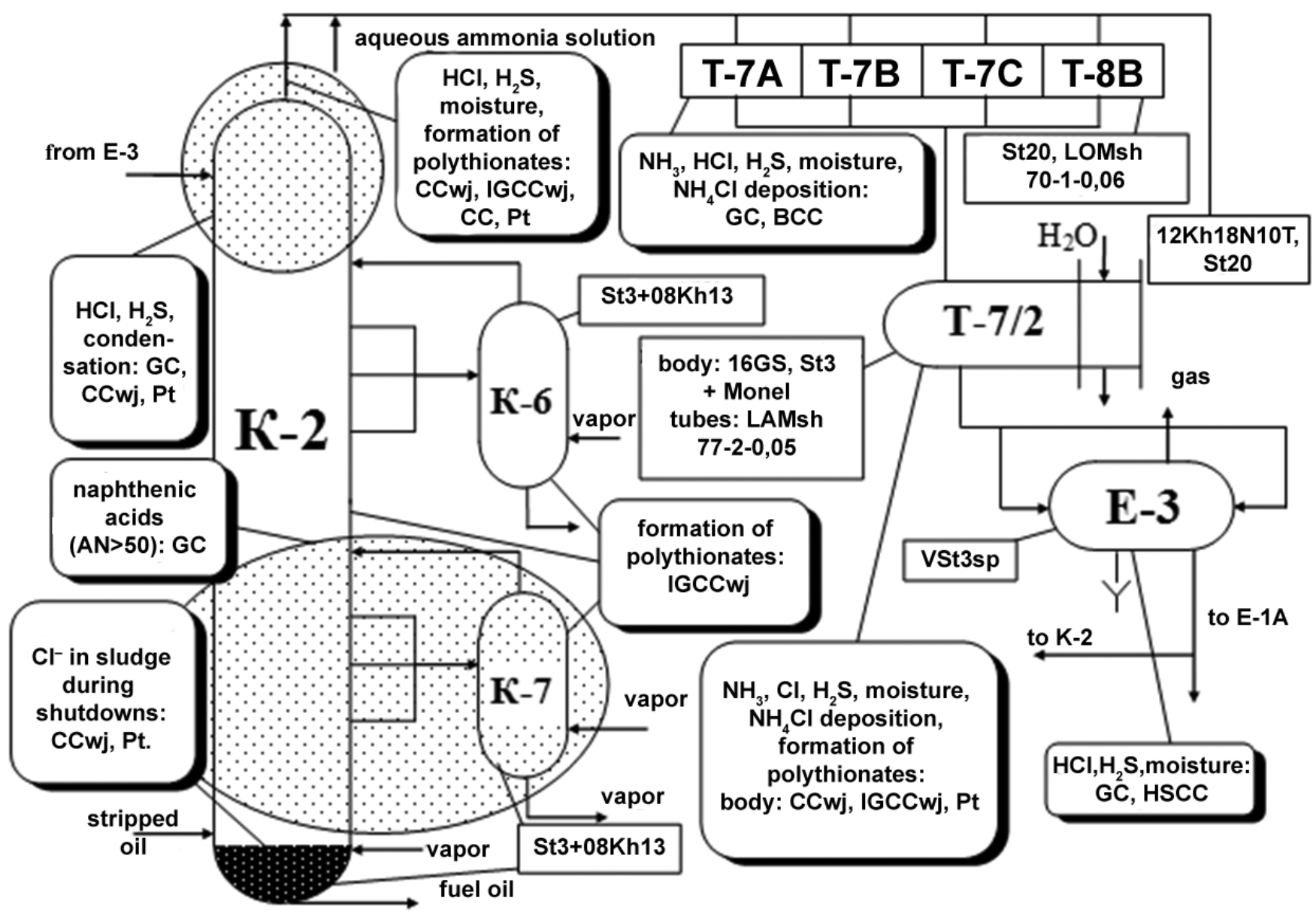

Fig. 1. ELOU-AT-6 unit (production enterprise "KINEF"). Atmospheric column. Possible damage and materials used. GC - general corrosion; CCwj - corrosion cracking of welded joints; IGCCwj - intergranular corrosion cracking of welded joints; CC - corrosion cracking of chromium-nickel stainless steel; HSCC - hydrogen sulfide corrosion cracking (delamination); $\mathrm{BCC}$ - brass corrosion cracking; $\mathrm{Pt}$ - pitting corrosion of stainless steel; AN - acidity number.

Table 2. Examples of corrosion cracking in welded joints, weld adjacent zones, and cladding layers of columns manufactured with cladding layers of steel $08 \mathrm{Kh} 13$ at an AVT-6 unit at production enterprise "KINEF".

\section{Column}

Evaporation column

Atmospheric column

Stripper column

Vacuum column

\section{Service life until degradation,} years

28

28

28-30

26

\section{Degradation location}

Top

Top, middle

Top, middle, bottom

Top, middle, bottom 
Table 3. Corrosion damage of welded joints and weld adjacent zones of cladding layers in hydrogenation product stabilization columns at reforming units of production enterprise "KINEF".

\begin{tabular}{cccc}
\hline Unit & Commissioning year & $\begin{array}{c}\text { Service life until } \\
\text { degradation, years }\end{array}$ & Degradation location \\
\hline L-35-11/300 & 1966 & 31 & top \\
\hline L-35-11/600 & 1969 & 28 & $\begin{array}{c}\text { top } \\
\text { middle } \\
\text { bottom }\end{array}$ \\
\hline LCh-35-11/600 & 1972 & 26 & top \\
\hline LCh-35-11/1000 & 1980 & 19 & $\begin{array}{c}\text { top } \\
\text { bottom }\end{array}$ \\
\hline
\end{tabular}

In order to select a possible material for the cladding layers, we performed industrial tests in the operation mode of oil processing units and laboratory studies of the pitting corrosion resistance of steels belonging to various classes (12Kh18N10T, 10Kh17N13MZT, 08Kh21N6M2T, 08Kh22N6T, and 015Kh18M2B) in electrolyte solutions simulating aqueous corrosion media [2]. It was found that steels containing molybdenum additives, namely $015 \mathrm{Kh} 18 \mathrm{M} 2 \mathrm{~B}$ ferritic steel, 08Kh21N6M2T austeniticferritic steel, and $10 \mathrm{Kh} 17 \mathrm{~N} 13 \mathrm{MZT}$ austenitic steel, were most resistant to pitting corrosion in the oil processing operation mode. The results obtained totally agree with the existing concept on the effect of alloying additives on the pitting resistance of steels, including the quantum-chemical ideas on the effect of alloying elements on pitting resistance: since their d-orbitals are incomplete, they are acceptors of iron d-electrons.

It follows from the data on the pitting resistance of steels that it is expedient to use molybdenum alloyed ferritic steels (such as $015 \mathrm{Kh} 18 \mathrm{M} 2 \mathrm{~B}$ ) as the cladding material instead of $08 \mathrm{Kh} 13$ steel that is susceptible to pitting corrosion in all vessels at all operation stages of oil processing plants. Molybdenum alloyed steels, such as 08Kh21N6M2T or $10 \mathrm{Kh} 17 \mathrm{~N} 13 \mathrm{MZT}$, can be recommended for other equipment parts instead of Kh18N10T type steels (12Kh18N10T, 08Kh22N6T, 08Kh22N10T).

Until steel $08 \mathrm{Kh} 13$ has been replaced by another steel with higher pitting resistance, we believe that, as long as the existing equipment made with $08 \mathrm{Kh} 13$ steel cladding is still in operation, it is necessary to introduce a system of inhibitor protection of $08 \mathrm{Kh} 13$ steel from general and pitting corrosion during steam treatment, since inhibition of pitting at this stage may also hinder the development of pits in all subsequent operation modes.

It should be noted that there is no clear concept in the literature as to which classes of chemical compounds can serve as inhibitors of pitting corrosion. When selecting compounds to be tested as pitting corrosion inhibitors, we relied on the concept of complexation in the pitting initiation and inhibition, namely, that inhibition should involve anions with high nucleophilic properties (the leaving nucleophiles), as well as on data on their efficiency as inhibitors of general corrosion of steels in aqueous solutions. 


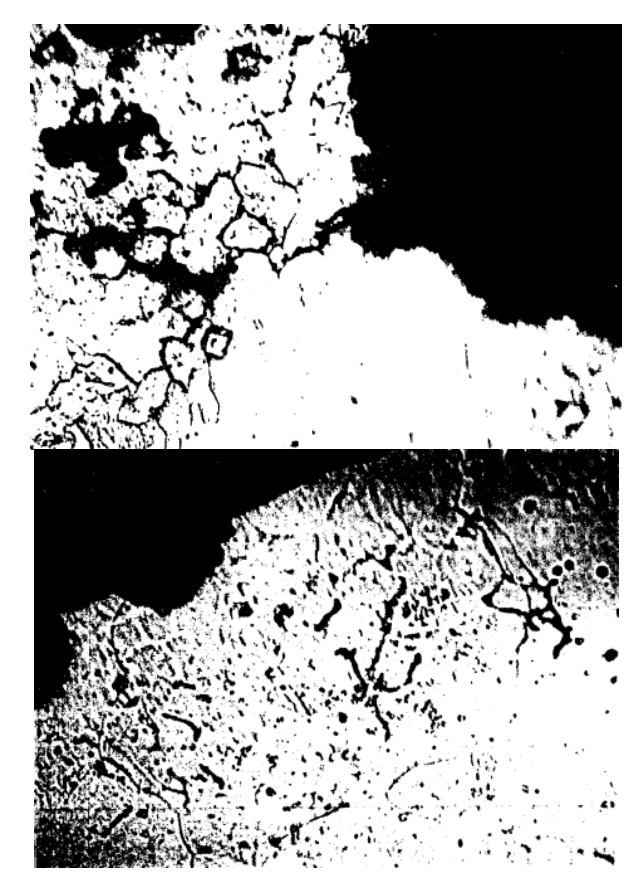

(a)

Fig. 2. Hydrogenation product stabilization column L-35-11/600 at a reforming unit, x500: (a) pitting - start of corrosion cracks; $(b)$ the metal zone of an austenitic welding joint.

Laboratory studies on the efficiency of a number of inhibitors based on the methods in GOST (State Standard) 9.912 [3] as inhibitors of general and pitting corrosion of 08Kh13 steel during steam treatment of equipment allowed us to recommend sodium nitrite, "NDA" inhibitor, and mixtures of the latter with sodium tripolyphosphate (1:1) [4]. If sodium nitrite and "NDA" inhibitor are added to electrolyte solutions, the main indicators of pitting resistance for steel $08 \mathrm{Kh} 13$ become similar to those of non-inhibited steels alloyed with molybdenum and containing higher chromium concentrations.

Pits nucleated during steam treatment can grow during equipment shutdowns or in working operation modes and can act as corrosion cracking initiators. Currently there are no normative documents on the duration of equipment steam treatment and the maximum acceptable concentrations of corrosive components in steam treatment condensates below which the probability of pit nucleation decreases. These data are not available in literature, either.

Based on the results of chemical and electrochemical studies on the liability of austenitic steels to pitting corrosion (using 12Kh18N10T steel as an example) in electrolyte solutions simulating the composition of steam treatment condensates, we have found that the pitting factor as well as the galvanostatic and potentiodynamic bases of pitting resistance depend not only on the concentrations of corrosive anions but also on their ratio in solutions [5].

In order to forecast the probability of pit nucleation in steam treatment condensates before equipment repair, we were the first in the world practice to propose a system of correlation relationships and an algorithm for the calculation of pitting resistance indicators of austenitic steel in sensitized state depending on the condensate composition [5]. Studies 
showed that the steam treatment operation should be carried out at concentrations in drainage waters not exceeding the following values: thiosulfate ions, no more than $5 \mathrm{mg} / \mathrm{l}$; chloride and sulfate ions, no more than 100-150 mg/l. Furthermore, the concentration of sulfate ions may be up to two times higher than that of chloride ions, but the opposite ratio is unacceptable. The probability of pit initiation during steam treatment and subsequent growth on austenitic steels, particularly on sensitized areas (welded joints), during repair and subsequent operation of units in working mode decreases considerably provided that the recommended values are observed.

A special series of studies was devoted to inhibitor protection of crude oil distillation plants in working mode [6,7]. Detailed studies showed that contemporary industrial amidoimidazoline inhibitors are complex mixtures of mono-, di- and aminoamides, imidazoline bases, quaternary salts, as well as unreacted polyamines and organic acids.

It has been found that inhibitors of amidoimidazoline series are characterized by "ageing", i.e., variation in the technical and physicochemical characteristics in the course of time: product stratification, decrease in solubility in gasolines, abrupt (sometimes by an order) decrease in protective properties. These processes start in industrial products as early as after $\sim 3$ months of storage. "Ageing" changes the hydrophobic-hydrophilic balance of molecules and increases the liability for micellization, which, along with a decrease in adsorption capability, impairs their efficiency $[1,6,7]$.

We have found that "ageing" of amidoimidazoline inhibitors can give rise to:

- an increase in the content of a secondary amide due to imidazoline hydrolysis;

- an increase in the content of free amine and acid due to amide hydrolysis;

- formation of diamides from an amide and an acid; formation of salts of carboxylic acids and imidazoline; condensation of imidazoline and carboxylic acid to give an amidoimidazoline; complex condensation of imidazoline and amide.

The occurrence of these reactions and formation of products with high molecular masses (polyamidines) result in stratification and formation of deposits in the products, decreases the solubility (dispersability) in gazolines (water) and the critical micelling concentration in water-salt systems, and decreases the adsorption capability of inhibitors and their efficiency.

Though inhibitors of the amidoimidazoline series protect carbon steel from general corrosion, they do not prevent the local corrosion sites from growth. During industrial tests we observed the formation of pits in the presence of amidoimidazoline inhibitors even on carbon steel St20 that is not susceptible to pitting.

It was shown that the main reason of the ability of amidoimidazoline inhibitors to cause pitting on steel is that at $\mathrm{pH} 5.5-6.5$, i.e., the oil processing $\mathrm{pH}$ range, they preferentially inhibit the anodic reaction but do not inhibit the cathodic reaction of depolarizer reduction, and some of them even accelerate it. As a result, they should be attributed to the category of "dangerous" inhibitors. 
As we have shown [7], the corrosion rates and types in all crude oil processing columns call for a revision of the traditional scheme of inhibitor injection that was proposed over 50 years ago. In addition to the traditional points of inhibitor injection into the overhead lines of evaporation and atmospheric columns, we proposed to inject an inhibitor:

- to the reflux lines of evaporation, atmospheric, and stabilization columns and gasoline redistillation columns;

- to the recirculation reflux lines of atmospheric columns;

- to the feed and to the overhead lines of the stabilization column and gasoline redistillation columns;

- to the overhead line, the top and middle recirculation lines of the vacuum column.

This scheme of inhibitor injection ensures the protection of not only condensation cooling equipment of the upper loop, and to a small extent the top parts of the evaporation and atmospheric columns, but also corrosion protection of the top and middle parts of evaporation and atmospheric columns, stripping columns, condensation cooling equipment (both in the overhead lines and as a whole), stabilization columns, gasoline redistillation columns, and vacuum columns.

A fundamentally new approach to the selection of starting products and reactions for synthesizing versatile volatile inhibitors of atmospheric corrosion (VIAC) based on correlation analysis of the dependence of the VIAC protective capability on their physicochemical and molecular properties allowed a new class of VIACs, viz., Schiff and Mannich bases, to be synthesized [8-12]. The inhibitor with conventional name VNKh-L408 is the most efficient. It is a fungicide and protects a wide range of ferrous and nonferrous metals, including silver, cadmium, zinc, magnesium, tin, copper and its alloys from atmospheric and biological corrosion.

A fundamentally new method for deposition of inhibitors onto metals by electrostatic field sputtering has been proposed [13]; it was not reported in literature before. This method allows the critical time of metal transition to the stable passive state to be minimized due to fast inhibitor adsorption, ensures inhibitor ingress into stagnant equipment zones and uniform inhibitor distribution on the surface being protected, decreases inhibitor evaporation, and strongly enhances the protective properties in comparison with the traditional application methods.

To date, a series of new normative technical documents (RD) have been elaborated and are being implemented in order to solve the corrosion problems at domestic oil refineries:

- "Methodical guidelines for protection of welded joints in equipment and pipelines of process units of oil refineries from corrosion cracking"; 
- "Methodical guidelines on corrosion protection of equipment and prevention of salt deposition in equipment of units for preliminary hydrotreatment of gasolines, jet and diesel fuels", and

- Operational procedures and updates to regulations for equipment protection in case of reduced load, during shutdowns, in case of changes in feed quality, and for equipment preservation, in relation with materials used, operating conditions, shutdown duration, and with a system of quality assurance during preservation and subsequent reactivation of units.

\section{Conclusions}

1. The experience of operation of an oil refinery and corrosion problems therein have been reviewed. An oil refinery is considered as a common organism whose units are operated sequentially: "start $\rightarrow$ production mode $\rightarrow$ shutdown (for repair or due to other reasons) $\rightarrow$ steam treatment $\rightarrow$ drying $\rightarrow$ repair $\rightarrow$ start $\ldots$ etc.", and corrosion damage is determined by the joint effects of the process media at all operation stages.

2. For the first time in worldwide practice, experimental data concerning the corrosion damage of equipment at domestic crude oil processing units have been collected and systematized, and corrosion charts have been created.

3. Methods for equipment protection from local and downtime corrosion as well as issues of material selection for the cladding of inside surfaces of vessels and pipelines have been discussed and proposed.

4. A new up-to-date scheme for inhibitor protection of oil processing units during operation has been proposed.

5. A new approach to the selection of starting products and reactions for synthesizing versatile inhibitors of atmospheric corrosion has been proposed. A new versatile fungicide inhibitor, VNKh-L-408, has been synthesized using this approach.

6. A series of new normative technical documents (RD) have been elaborated and are being implemented in order to solve the corrosion problems of units at domestic oil refineries.

\section{References}

1. V. V. Burlov, A. I. Altsybeeva and I. V. Parputs, Zashchita ot korrozii oborudovaniya NPZ (Corrosion protection of oil refinery plant equipment), Saint Petersburg, Khimizdat, 2005, 248 pp. (in Russian).

2. A.I. Altsybeeva, V.V. Burlov, T.M. Kuzinova, V.L. Sokolov and S.M. Reshetnikov, Korroz.: mater., zasch., 2009, no. 3, 6 (in Russian).

3. GOST (Russian State Standard) 9.912-89 ESZKS (Unified system of corrosion and ageing protection). Stali i splavy korrozionnostoikie. Metody uskorennykh ispytanii na stoikost' $k$ pittingovoi korrozii (Corrosion-resistant steels and alloys. Methods of accelerated testing for resistance to pitting corrosion), Moscow, Gosstandart, 1989, 18 pp. (in Russian). 
4. A.I. Altsybeeva, V.V. Burlov, T.M. Kuzinova, V.L. Sokolov and S.M. Reshetnikov, Korroz.: mater., zasch., 2009, no. 1, 16 (in Russian).

5. V. V. Burlov, T. P. Parputs, A. I. Altsybeeva, T. M. Kuzinova and S. M. Reshetnikov, Korroz.: mater., zasch., 2009, no. 6, 18 (in Russian).

6. A. I. Altsybeeva, V. V. Burlov, T. M. Kuzinova, G. F. Palatik and S.M.Reshetnikov, Korroz.: mater., zasch., 2006, no. 1, 25 (in Russian).

7. A. I. Altsybeeva, V. V. Burlov, V. L. Sokolov and G. F. Palatik, Korroz.: mater., zasch., 2007, no.5, 23 (in Russian).

8. A. I. Altsybeeva, V. V. Burlov, N. S. Fedorova, T. M. Kuzinova and G. F. Palatik, Korroz.: mater., zasch., 2009, no. 9, 22 (in Russian).

9. A. I. Altsybeeva, V. V. Burlov, N. S. Fedorova, T. M. Kuzinova and G. F. Palatik, Korroz.: mater., zasch., 2009, no. 10, 25 (in Russian).

10. A. I. Altsybeeva, V. V. Burlov, N. S. Fedorova and T. M. Kuzinova, Korroz.: mater., zasch., 2010, no. 6, 26 (in Russian).

11. A. I. Altsybeeva, V. V. Burlov, N. S. Fedorova and T. M. Kuzinova, Korroz.: mater., zasch., 2010, no. 7, 17 (in Russian).

12. A. I. Altsybeeva, V. V. Burlov, N. S. Fedorova and S. M. Reshetnikov, Korroz.: mater., zasch., 2011, no. 4, 33 (in Russian).

13. A. I. Altsybeeva, V. V. Burlov and T. M. Kuzinova, Korroz.: mater., zasch., 2006, no. 3, 28 (in Russian). 